\title{
Fundamental Theory for Successful A.I. Adoption in Industry
}

\author{
Abhishek Dutta*, Nivedita Roy ${ }^{* *}$ \\ * Hewlett Packard Enterprise \\ **Accenture \\ DOI: $10.29322 / I J S R P .10 .11 .2020 . p 10769$ \\ http://dx.doi.org/10.29322/IJSRP.10.11.2020.p10769
}


Abstract- The world, which was just globally flat (Friedman, 2005) earlier, has suddenly turned to ether and real-time decision making by systems has become the need of the hour. This transformation is ushering in the age of global digitization. This actuation towards transformation and digitization (Kapur \& Wong, 2020) has motivated businesses to look towards artificial intelligence (Huang \& Rust, 2018) or A.I., as the only relevant solution. However, A.I. is still young as a technology and in-spite of all the drive and advancements that we have seen in recent times, the technology is neither matured nor standardized and unbiased. Hence, formulating the theoretical principles for successful and safe A.I. adoption, has become a quintessential reality. This paper looks to review and deliberate on the issue and drive discussions to lay down the five fundamental principles for successful A.I. adoption, which will lessen the burden of bias, owing to this new technology incubation and utilization.

Index Terms- Artificial Intelligence, Behavioral Strategy, Change Management, Innovation Management, Survey Research, Sentiment Analysis, Technology Strategy.

\section{INTRODUCTION}

$\mathrm{W}$ e are living in a world at the edge of global transformation, heralding the advent of global digitization! It is different from the prior era of digital globalization (Manyika, Lund, Bughin, Woetzel, Stamenov, \& Dhingra, 2016), where matured and standardized digital platforms aided in connecting the world. Digital globalization (Manyika et al., 2016) actually began with the world as a whole, increasingly communicating information on digital platforms. It soon paved the way for the electronic boom aeon, where the consumer world interacted socially, as well as conducted business through digital and web streams. However, the initial success of the electronic boom was underplayed in its first wave, owing to lack of standardization and general consumer awareness about digital platforms, thereby misleading its assessment. This was back in 1990s, and the business to consumer world had just begun to spiral out of control, thus ending prematurely with the dotcom bubble burst (Ofek \& Richardson, 2003). However, after twenty years of learning, adaptations and standardizations in terms of expectations and government policy undertakings, we have finally reached a point of absolute adoption where majority of consumers are not only well-versed, but also, prefer interacting, purchasing and surviving on pseudo-digital mode of life!

However, during the same time the business to business (b2b) world of larger corporates, enterprises and the public sector organizations had held on to the traditional methods of business administration, which relied on face to face interactions, personal touch and proof of ownership. This was primarily owing to the high value of purchases made on enterprise funds requiring assessment of underlying incumbent responsibility and following fair practice frameworks set decades ago to be followed to the letter. Hence, the business to business world, owing to a lack of cumulative interest, had only made marginal progress towards adoption of digital practices in administration, as well as purchasing through digital modes. Currently, in a world socially distanced owing to covid-19 (Mathur, 2020; Nielsen, 2020), we have seen a sudden drive towards full scale digitization, thus initializing the onset of global digitization.

\section{A. Industry Need}

In the current age of global digitization, there is an acute lack of standardized immersive digital platforms (Kaplan- Rakowski \& Meseberg, 2018) that enables to engage more human senses and thereby emulate face to face connect. Today, we do have the basic framework of immersive technologies, digital platforms, intelligent systems and real-time but seamless computation on cloud (Katzan, 2008). However, covid-19 has shown that the world requires much more in terms of integrated platforms and systems (Kapur \& Wong, 2020). The platforms cannot be individual systems or tools, anymore. It is required to do much more such as:

1) Capturing audience through immersive and experiential marketing,

2) Helping customers assess utility,

3) Provide user and analyst feedback,

4) Showcase value added services,

5) Capture and nurture interests expressed to potential business leads,

6) Allow customized approaches to convince the buyers and finally

7) Flow of data to standardized and matured customer relationship management or CRM systems.

Today, most of these systems are available as piece-meal solutions and there is hardly any platform which can provide all these services in a unified manner. To make matters worse, we also would need to develop overall standardization and there is also a growing concern that the individual standardizations inbuilt into these stand-alone technology systems will be inadequate (Cargill, 2011). Further, the concept of deriving return on investment for digital purchase (Cargill, 2011) is still a topic of hot debate across the business world.

However, in spite of the current predicament, we have been forced to adopt generic digital platforms to survive!

\section{B. Hypothesis}

Hence, affliction inflicted by covid-19 has provided an unprecedented impetus, resulting in paradigm shifts in the traditional way of being human. The impact has been immense in the natural way of conducting business, especially in the high value business to business purchases for the enterprise segment. The world, which was just flat earlier (Friedman, 2005), has suddenly turned into ether! Thus, there is a dire need to standardize principles of successful industry adoption, which will support development of A.I. driven digital and smart marketing \& sales engine (MASE) or marketing and sales specific container systems (Hardy, 2018)!

\section{Marketing \& Sales Engine (MASE)}

The MASE systems will provide an integrated and immersive marketing route. It will not be restricted to only easy deployment of technology, but going a mile further, it is going to usher in smart 
container systems. These smart containers will eventually be able to -

1) Crawl, procure and collect information from the internet and third party databases on market conditions

2) Estimate expected demand through social listening

3) Determine marketing content to be used in campaigns

4) Optimize the content delivery mode or marketing activity, based on expected return on investment

5) Recognize the digital signals through gestures in video and text analysis of chats with audience

6) Score and route potential leads to specific sales personnel, based on experience, skill, availability and success rate and

7) Guide the sales team on likes and dislikes of a specific customer in order for sales to personalize their approach and maximize deal closure

This would be the end to end role of smart container or MASE, from generating a lead in the digital to closing a deal.

And through this extensive digitization, data explosion and requirement for decision support intelligence, artificial intelligence or A.I. (Huang \& Rust, 2018) is being commonly identified by enterprise businesses as the undisputed solution to help manage data, systems, computation and finally decision making.

\section{IDENTIFY, RESEARCH AND COLLECT IDEA}

In this article, assessment of A.I. technology for business usage has been performed using the following methodology -

\section{A. Secondary Research}

Over the past two years, extensive research has been undertaken on the adoption criteria that every system or enterprise organization must consider to incubate and implement A.I. technology in its business functions. The focus was primarily on marketing and sales functions.

\section{B. Primary Research and Focus Group Studies}

The primary research is based on decades of professional experience of nine (9) business leaders across corporate and startup environments. These leaders are looking for avenues to optimize cost and enable their sales and marketing teams to evolve and transform. The information was captured by conducting interviews with two or more leaders (from the sample size of nine), over three different focus group studies. Individual connections were made for primary research discussions on the importance of A.I. in a post covid-19 era and their thoughts on the principles of adoption were taken into account.

\section{Test and Control Study on Experiential Learning}

Pilot studies to review adoption and absorption of any new technology, be it A.I. or machine learning technology, were conducted using test and control group technique on eighty marketing and sales personnel. These personnel were spread across asia, europe\& americas. This test group of forty (40) sample size was exposed to the new CRM systems or A.I. \& data science recommendation engines. Control group was composed of separate fifty (50) professionals, who were not aware of the systems or recommendations and did not receive any recommendation either. The raw data procured through voice of user feedback for the test sample size, were one hundred and sixty (160) observations and are provided in the supplement document submitted, named 'Data'. It is a comma separated file type.

The advanced programs selected to support the test group and assess adoption were:

1) Attribute analysis (2013): Here customer or account attributes were focused on providing sales organization with a target list of customers to pursue, as these customers seemed to be a more accurate fit for a given product based on attributes studied. The study was conducted in 2013 and qualitative and quantitative observations of adoption were noted.

2) Marketing Planning customer relationship management system or CRM: New CRM system was launched to perform marketing planning with channel partners and analyze performance in realtime.

3) Predicting demand pattern from digital marketing campaign executions (2019): Here survey data from field marketing managers and performance data from digital marketing campaign executions have been analyzed. The analysis of the foundational principles or factors has been done through time series studies. The weights that arrived from the analysis were further fed as starting and reference points in recursive neural networks to set up an integrated campaign recommendation engine or RE by geography, product portfolio, periodicity, seasonality and industry vertical. The study was conducted in 2019.

4) Implementation of natural language processing (NLP) in marketing business processes (2020): Here pipeline data from CRM systems and content from campaigns were used as input to natural language processing units and long short term memory i.e. LSTM neural network was trained on the correct outputs to set up an automated engine for marketing campaign recommendation. The output could be used by anyone to get recommendations on marketing campaigns and content would generate better interest, based on and mapped to specific audience attributes. The study was conducted in 2020 .

\section{Variables}

To deduce the fundamental principles for successful A.I. adoption, sentiment or polarity score was used as the primary variable. This helped in understanding positive or negative sentiment from voice of user feedback or bias towards technology or systems. This text feedback was primarily observed from the test and control group experiment and hence the variable sentiment was used to analyze test and control group experiment, primarily.

\section{WRITE DOWN YOUR STUDIES AND FINDINGS}

A. Secondary Research 
From secondary research we found that A.I. as a technology is still young. To make matter worse, enterprises and organizations have not matured adequately to internalize and integrate the technology. The fundamental issue lies in the fact that the input to these systems is quintessentially biased (Silberg \& Manyika, 2019), thus rendering systems we train to be eventually naïve.

\section{Bias (Silberg \& Manyika, 2019) exists in the form of -}

1) Bias in data collection modalities (Silberg \& Manyika, 2019): Data collection is performed using data sampling by human beings and is thereby prone to human bias. It needs to be normalized or scaled down by leveraging statistical techniques of selecting sample, while ensuring adequate sample size.

2) Bias in input data and architecture (Silberg \& Manyika, 2019): Data architecture defines how unification of data from different databases, platforms and even different data entry systems occur. Gaps, auto-fills, proxies are today a common practice and create noise in data. Further, we face immense challenges in integrating data from different platforms, often resulting in incorrect setup of fields or parameters in the final database. This renders the entire data architecture erroneous and unusable.

Also this input data is what is primarily used by A.I. network to learn about the underlying patterns to analyze, making it the most crucial element for ensuring efficacy of the output. Thus, it is imperative to label and teach the A.I. system to understand the "relevance" of a $>$ time-period, b> sensitivity of information like ethnicity or gender and location, $c>$ imputation and proxies in data and $d>$ identify, segregate and apply discriminatory measures to unprecedented scenarios.

Hence, a dynamic, systematic, integrated and intelligent data architecture needs to be in place for incorporating feedback and avoid bias in data architecture.

Bias are predominantly of the following form:

1) Bias in setting up correct network architecture for analysis: Selection of number of nodes, neurons and weightage for any A.I. architecture is typically driven by the developer (Silberg \& Manyika, 2019). These selections are extremely important in arriving at the correct result. In practice we have often found that biased setup of these network architecture results in incremental processing time and decrease in accuracy. Thus, this bias needs to be standardized over time through human intervention and mapping for successful deployment of the technology.

2) Human bias in selection of correct algorithm for a given problem: Algorithm introduced for training the system often embeds human prejudice and hence it is prone to bias, if not peer reviewed and tested (Silberg \& Manyika, 2019).

Test and Control Study on Experiential Learning

Textblob lexicon based python sentiment analysis package has been used to analyze the text feedback received. Average sentiment of all user reviews (as depicted in the python code supplementary) were positive with a polarity score of ' 0.22 ' (Range: -1 to +1 , where lesser than or equal to 0 denotes negative/ neutral sentiment $\&>0$ denotes positives sentiment). Through adoption and absorption studies, using test and control methodology, a uniform trend was observed $\square$

1) $\sim 53 \%$ (Table 2) of the test group was biased against receiving recommendations, during the first week and required handholding and incentives to use the systems. This bias existed, in spite of positive feedback about the systems or engines from their peers, belonging to the same test group. Average sentiment of all user reviews were positive with a polarity score of ' 0.2 ' (Table 1)

2) During the second week of exposure to the systems or recommendation engines, the test group provided feedback that the systems were not helping. When discussed further, it was identified that the $\sim 63 \%$ (Table 2 ) of the study personnel expected more definitive result from the systems or engines. For instance, this $\sim 63 \%$ (Table 2 ) of the test group, expected the customer to be welcoming the sales \& marketing teams for a meet during their first call, rather than trying their sales tactics. Whenever that didn't happen, they lost faith in the recommendation provided by the automated engine. Average sentiment of user reviews were positive with a polarity score of ' 0.1 ' (Table 1)

3) By fifth week and further $\rightarrow$ With a third and fourth week follow-up or hands-on practice on recommendations or systems respectively, whenever a success was achieved from the recommended list $\rightarrow$

a. About $68 \%$ (Table 2) of the test group achieved success in generating a business lead or being able to successfully complete marketing planning. However, only some of them attributed the same to the correct recommendations or support provided by the system/ engine.

b. Rest attributed success to follow-ups performed by the individual and thereby believed that success was achieved through patience.

c. Post the study, when the observations were complied, some of the test group had generated either more leads or performed standardized marketing planning more efficiently, than those who didn't use the support from the smart systems.

d. Average sentiment of user reviews were positive with a polarity score of ' 0.24 ' (Table 1 ). Detailed sentiment or polarity score available in supplement document submitted named dfO. It is a comma separated value file type.

4) One year later (with no Refresh provided) $\rightarrow$ When the voice of the user feedback was reviewed to plan for the next cycle or business year, $75 \%$ (Table 2) of the test group requested for the supporting recommendations or planning systems. Further, the test group had recommended these new systems to their counterparts in the control group as well as key assets, aiding in their previous cycle performance. Average sentiment of user reviews were positive with a polarity score of ' 0.40 ' (Table 1 ). 
Table 1

Sentiment or Polarity Average Pivot by Week

\begin{tabular}{ll}
\hline Week & Polarity or Sentiment Score \\
\hline 1.00 & 0.19 \\
2.00 & 0.10 \\
5.00 & 0.24 \\
53.00 & 0.40 \\
\hline
\end{tabular}

Table 2

Respondent Sentiment \% Split by Week

\begin{tabular}{llll}
\hline Week & $\begin{array}{l}\text { Sentiment } \\
\text { Label }\end{array}$ & $\begin{array}{l}\text { Respondent } \\
\text { Count }\end{array}$ & $\begin{array}{l}\text { \% (Respondent } \\
\text { Count per } \\
\text { Sentiment/Week) }\end{array}$ \\
\hline 1 & positive & 19.00 & $47.50 \%$ \\
& negative & 21.00 & $52.50 \%$ \\
2 & positive & 15.00 & $37.50 \%$ \\
& negative & 25.00 & $62.50 \%$ \\
5 & positive & 27.00 & $67.50 \%$ \\
& negative & 13.00 & $32.50 \%$ \\
53 & positive & 30.00 & $75.00 \%$ \\
& negative & 10.00 & $25.00 \%$ \\
\hline
\end{tabular}

\section{B. Focus Groups and Primary Research}

Here, based on primary discussions and group studies, the following was noted -

1) $100 \%$ of the business and technology leaders (study group), participating in the study, believed that A.I. is of ubiquitous importance, as we step into a post covid-19 era.

2) $70 \%$ of the study group stated that from data management to systems making decisions in real-time, most computation will be needed to be automated and seamless through trained intelligent machines.

3) $40 \%$ of the study group believed that successful incubation and implementation of A.I. will require an absorption at the chief executive officer level. This means the chief officers of an enterprise must adapt to and adopt A.I. policies centrally and this should be transformed into a best practice. It requires to be at the root or at the core of any organization.

4) $20 \%$ of the study group elucidated that as maturity of A.I. is currently a big question, management of bias in A.I. through training and human supervision is mandatory.

5) $50 \%$ of the study group explained that like with any new technology or system, first users are always exposed to bugs, which will need to get fixed. However, it will be of absolute importance to ensure that the human users understand the technology, its limitations and design safeguards to protect against incorrect output from systems during the initial training phase.

6) $100 \%$ of the study group believed that it's time to frame the basic rules which may enable enterprises and organizations to be A.I. ready and help them set expectations while navigating adoption process.

\section{Focus Group Citations}

1) COVID-19 has ushered in a new normal that has altered the complexion of business. With more than two-thirds of the buyer's journey already digital in a pre-COVID-19 world, the acceleration to a fully digital marketing motion has never been more important. A.I. allows for closer customer engagement in a time defined by social distancing. With digital nurturing and data mining capabilities fueled by A.I., marketing organizations can help their organizations remain relevant and helpful to buyers in a fully virtual world (Allison Cerra, 2020)

2) Transformation is a cultural change (Fred Van Der Wijk \& Bhooshan Parikh, 2020)

3) Humanize \& make A.I. explainable (Mohan K \& Nivedita Roy, 2020)

4) In the advent of the new normal previous breakthroughs in terms of digital traction have been fast forwarded to a huge extent. However in the fields of consumer insights and identifying differentiators a huge challenge has arisen in the face of overwhelming saturation in digital/social marketing. This is where a comprehensive A.I. play, both at the back end in terms of identification of opportunities and at the consumer end through identifying sharp psychographic and demographic patterns for targeted messaging can help organizations surge ahead (Anirban Tarafdar, 2020)

5) A key thing for A.I. to enrich our life and the world around us would be to understand and respond to human interactions in a way that is more human like and is not restricted to templated responses. Today A.I. has reached human parity milestones in multiple facets like object recognition, speech recognition and comprehension etc. and we have started to rely on A.I. to make decisions that we have traditionally relied on human intellect. While these are exciting times, it is really important that all these technologies are grounded in ethics. As enablers of the A.I. and associated technologies, we should take the responsibility of baking in those ethical principles from the ground up. This is no different than the good values and education that we endow in our children (Debarshi Bhowal, 2020)

6) A.I. is a transformational change and most organizations are adopting to the change. This has a far wider spectrum and most don't realize how they can benefit from the adoption (Ayan Bagchi, 2020)

7) Systems should have free speech (Abhishek Dutta, 2020) 
Table 3

Focus Group Discussion Summary

\begin{tabular}{|c|c|c|c|c|}
\hline $\begin{array}{l}\text { S. } \\
\text { N } \\
\text { o. }\end{array}$ & $\begin{array}{l}\text { Business } \\
\text { Leader } \\
\text { Name }\end{array}$ & $\begin{array}{l}\text { Designati } \\
\text { on }\end{array}$ & $\begin{array}{l}\text { Organizati } \\
\text { on }\end{array}$ & $\begin{array}{l}\text { What factor will } \\
\text { drive Artificial } \\
\text { Intelligence (AI) } \\
\text { Adoption in B2B } \\
\text { Market }\end{array}$ \\
\hline 1 & $\begin{array}{l}\text { Allison } \\
\text { Cerra }\end{array}$ & $\begin{array}{l}\text { WW VP } \\
\text { of } \\
\text { Geograph } \\
\text { y } \\
\text { Marketing }\end{array}$ & $\begin{array}{l}\text { Hewlett } \\
\text { Packard } \\
\text { Enterprise }\end{array}$ & $\begin{array}{l}\text { Digital nurturing } \\
\text { and data mining } \\
\text { capabilities fueled } \\
\text { by A.I. }\end{array}$ \\
\hline 2 & $\begin{array}{l}\text { Nivedita } \\
\text { Roy }\end{array}$ & $\begin{array}{l}\text { Sr. } \\
\text { Manager, } \\
\text { Accenture } \\
\text { Managem } \\
\text { ent } \\
\text { Consultin } \\
\text { g }\end{array}$ & Accenture & $\begin{array}{l}\text { Make A.I. driven } \\
\text { Technology and } \\
\text { Recommendations } \\
\text { more explainable }\end{array}$ \\
\hline 3 & $\begin{array}{l}\text { Fred Van } \\
\text { Der Wijk }\end{array}$ & $\begin{array}{l}\text { WW } \\
\text { Director - } \\
\text { Channel } \\
\text { Marketing } \\
\text { Ops }\end{array}$ & $\begin{array}{l}\text { Hewlett } \\
\text { Packard } \\
\text { Enterprise }\end{array}$ & $\begin{array}{l}\text { A.I. needs to } \\
\text { transform } \\
\text { organizations } \\
\text { from the core \& } \\
\text { not from edges }\end{array}$ \\
\hline 4 & K Mohan & $\begin{array}{l}\text { WW } \\
\text { Analytics } \\
\text { Manager }\end{array}$ & $\begin{array}{l}\text { Hewlett } \\
\text { Packard } \\
\text { Enterprise }\end{array}$ & Humanize A.I. \\
\hline 5 & $\begin{array}{l}\text { Debarshi } \\
\text { Bhowal }\end{array}$ & $\begin{array}{l}\text { Principal } \\
\text { Engineeri } \\
\text { ng } \\
\text { Manager }\end{array}$ & Microsoft & $\begin{array}{l}\text { Make A.I. more } \\
\text { human like }\end{array}$ \\
\hline 6 & $\begin{array}{l}\text { Bhoosha } \\
\text { n Parikh }\end{array}$ & $\begin{array}{l}\text { Channel } \\
\text { Business } \\
\text { Manager }\end{array}$ & $\begin{array}{l}\text { Hewlett } \\
\text { Packard } \\
\text { Enterprise }\end{array}$ & $\begin{array}{l}\text { A.I. adoption will } \\
\text { increase through a } \\
\text { cultural change } \\
\text { with any } \\
\text { organization }\end{array}$ \\
\hline 7 & $\begin{array}{l}\text { Sharon } \\
\text { Hiu }\end{array}$ & Analyst & Canalys & $\begin{array}{l}\text { A.I. will find } \\
\text { increased adoption } \\
\text { when it augments } \\
\& \text { aids humans } \\
\text { with technological } \\
\text { advancement, } \\
\text { without creating } \\
\text { the situation } \\
\text { where people are } \\
\text { replaced }\end{array}$ \\
\hline 8 & $\begin{array}{l}\text { Anirban } \\
\text { Tarafdar }\end{array}$ & $\begin{array}{l}\text { Business } \\
\text { Counselor }\end{array}$ & Swiggy & $\begin{array}{l}\text { A.I. play both at } \\
\text { backend data } \\
\text { systems \& at the } \\
\text { edge of execution } \\
\text { will create the } \\
\text { differentiation } \\
\text { driving increased } \\
\text { adoption }\end{array}$ \\
\hline 9 & $\begin{array}{l}\text { Ayan } \\
\text { Bagchi }\end{array}$ & $\begin{array}{l}\text { Chief } \\
\text { Operating } \\
\text { Officer }\end{array}$ & $\begin{array}{l}\text { Reverside } \\
\text { Software } \\
\text { Solutions } \\
\end{array}$ & $\begin{array}{l}\text { Through } \\
\text { Organizational } \\
\text { Transformation }\end{array}$ \\
\hline
\end{tabular}

Based on the qualitative \& quantitative surveys and test $\&$ control studies conducted, it can be inferred that A.I. technology though capable, is still very culpable and thereby, requires training and time to mature! As with every new technology, A.I. too will face initial resistance and lack of interest in adoption by most users in any enterprise. However, with time, exposure and training, adoption will see a steep increase.

If biases (Silberg \& Manyika, 2019) in technology are not accounted for and the adoption process is not standardized (Fountaine, McCarthy, \& Saleh, 2019), the output of A.I. systems may prove to be erroneous in real-time industrial applications. Furthermore, this biased (Silberg \& Manyika, 2019) output will create unnecessary issues in how the business leaders will perceive benefits and adoption of this technology. It is imperative to arrest this potential of fear, uncertainty and doubt (FUD; Harsh, 2018) that may result from a rushed adoption of A.I., in business. Thus, bias (Silberg \& Manyika, 2019) in A.I. must be understood and scaled before it becomes a bias against A.I. (Silberg \& Manyika, 2019)!

\section{CONCLUSION}

Thus it is of utmost importance that we are able to derive and frame the fundamental principles of A.I. Adoption and drive standardization (Fountaine, McCarthy, \& Saleh, 2019).

Through research focused studies, discussions and collective experience in attempting to adopt A.I., we deduce that the following four fundamental principles will govern successful adoption of A.I, in the near future -

1) Systems should have free speech through integration (Thórisson, 2007), interconnectivity (Ornes, 2016) and interoperability (Dutta, 2014):

One of the fundamental issues across most enterprises and organizations, especially in the pre-cloud and kubernetes era, is that most companies have their data, interactions, meta- data and platforms setup in a decentralized way. The issue was in the fundamental vision where a connected computing and storage hardware situated in a secured customer or client location, albeit cost expensive, was of primary importance and value addition. However, since the onset of digital globalization and through the initiation of clustered computing in cloud, performed by search engine, that vision slowly started changing. With the advent of global digitization, the requirement today is to pivot to systems where platforms and systems within a same function need to be unified. For A.I. to work effectively, these various platforms or 
engines should be enabled to talk to each other freely through sharing of data.

Hence integration, interconnectivity and interoperability are of paramount importance.

2) A.I. needs to be a cultural change, transforming at the core (Ramakrishnan, 2019) and not from the edges (of any system):

This essentially suggests that for any system, be it an organization or even a robot, the adoption of A.I. should be a core principle at the heart of the organization, guiding all decision making.

The theory behind this principle is deduced through the test and control study. Based on observations and inference we found that in its nascent deployment phase, every new technology within any process or business requires time for adoption. During this period there are very few early adopters, owing to a myriad of reasons starting from bias and errors in the technology or system, to bias against change and learning new technology. However, with time, we see that the mind-set towards adoption and absorption changes drastically, making time invested critical for successful adoptability.

This time can only be derived if the top echelons of management and the chiefs of organizations make it a policy to drive business keeping A.I. at the core. Only then, enterprises will be able to achieve an effective adoption driving returns and benefits for any company.

3) Humanize A.I. by making it more explainable:

It essentially suggests that the human factor behind development and controllership of A.I. systems cannot be forgone.

The technology is currently biased and immature in its learning and it will require active human intervention to keep it in the correct learning curve. This underlying bias needs to be accounted for and scaled or corrected through humans governing their training. Eventually, someday A.I. maybe smart enough to stand on its own without any human intervention for it to work. Till then, we will need to ensure that A.I. systems are not misunderstood by their developers and users, but rather comprehended and nurtured by humans.

Hence, in a nutshell, true adoption can only be driven if developers humanize A.I. and make them easy to comprehend for human beings! It needs to be explainable!

4) Humanize Safeguard human beings by following the three laws of robotics (Salge, 2017):

Adoption of A.I. will mandatorily need to follow the three laws of robotics in any decision making, while arriving at the best solution for any scenario through computation of differential equations. It means that while selecting the most optimized path to solve a problem, A.I. or equivalent systems need to ensure that the solution is not prohibited by the three laws. If prohibited, A.I. computations need to iterate till it finds a proper solution, keeping the limitations in mind. The primary challenge in this is how to integrate the philosophy behind these rules in machine language while enabling an A.I. engine (Salge \& Polani, 2017). However the theory of empowerment (Salge \& Polani, 2017) may provide a natural solution to this issue, while ensuring the A.I. does not take steps which significantly harms its state vectors $($ (s) of the $Q(s, a)$ ), visualized and formulized during reinforcement learning (Tripathi, Ashwin, Guddeti, 2018).

These four principles will be relevant to all systems, starting from automation of an individual process to deployment of an intelligent decision support systems in an organization.

In conclusion, integration of A.I. is becoming inevitable, but the aforementioned fundamental principles will ensure less collective failures and thereby pave the path for a true, successful and easy adoption of A.I.

\section{ACKNOWLEDGMENT}

Allison Cerra, Fred Van Der Wijk, K Mohan, Debarshi Bhowal, Bhooshan Parikh, Sharon Hiu, Anirban Tarafdar, Ayan Bagchi and Rinku Chatterjee

\section{REFERENCES}

[1] C. F. Cargill, "Why standardization efforts fail," The Journal of Electronic Publishing, 2011, pp. 1-14.

[2] T. Fountaine, B. McCarthy \& T. Saleh, "Building the A.I.- powered organization," Harvard Business Review, 2019, pp. 1-2.

[3] Q. Hardy, "How cloud computing is changing management," Harvard Business Review, 2018, pp. 2-3.

[4] T. Friedman, "The world is flat: A brief history of the twenty-first Century (Book Style)," New York: Farrar, Straus and Giroux, 2005, pp. 1-1.

[5] A. Harsh, "Why we must remove fear, uncertainty, and doubt from A.I.," LinkedIn, 2018, pp. 1-2.

[6] M-H. Huang \& R. T. Rust, “Artificial intelligence in service," Journal of Service Research, 2018, pp. 155-172.

[7] R. Kaplan-Rakowski, \& K. Meseberg, "Immersive media and their future," In R. B. Branch, H. Lee, S. S. Tseng (Eds.). Educational Media and Technology Yearbook. Cham Springer, 2018, pp. 143-153.

[8] A. R. Kapur \& A. Wong, "Marketing metrics for an evolving World. Ondemand webinar," LinkedIn, 2020.

[9] H. Katzan, "Cloud computing, I-Service, and IT service provisioning," Journal of Service Science, 2008, pp. 57-64.

[10] J. Manyika, S. Lund, J. Bughin, J. Woetzel, K. Stamenov, \& D.

[11] Dhingra, "Digital globalization: The new era of global flows," McKinsey Global Institute, 2019, pp. 1-2.

[12] N. Mathur, "Covid-19 will hasten digital adoption, spend on cloud, A.I., and cybersecurity," Livemint, 2020, pp. 2-4.

[13] "Covid-19: The unexpected catalyst for tech adoption.” Nielsen, 2020, pp. 11

[14] E. Ofek, \& M. Richardson, "DotCom mania: The rise and fall of internet stock prices," The Journal of Finance, 2003, pp. 1113-1137.

[15] S. Ornes, "Core concept: The internet of things and the explosion of interconnectivity," Proceedings of the National Academy of Sciences of the United States of America, 2016, pp. 11059-11060.

[16] K. Ramakrishnan, "A.I. from exploring to transforming: Introducing the A.I. maturity framework," Element A.I., 2019, pp. 1-1.

[17] C. Salge, “Asimov's laws won't stop robots from harming humans. So we have developed a better solution," Scientific American, 2017, pp. 2-3.

[18] C. Salge \& D. Polani, "Empowerment as replacement for the three laws of robotics," Frontiers in Robotics and A.I., 2017, pp. 25. 
[19] J. Silberg \& J. Manyika, "Notes from the A.I. frontier: Tackling bias in A.I. (and in humans)," McKinsey Global Institute, 2019, pp. 1-6.

[20] K.R. Thórisson, "Integrated A.I. systems. Minds and Machines," Research Gate, 2007, pp. 11-25.

[21] A. Tripathi, T.S. Ashwin, R.M.R. Guddeti, "A reinforcement learning and recurrent neural network based dynamic user modeling system," IEEE 18th International Conference on Advanced Learning Technologies (ICALT), 2018, pp. 1-1

[22] A. Dutta, "Sustainable development in healthcare interoperability (IT) - New business opportunity review," International Journal of Engineering and Management Sciences, 2014, pp. 165-178.

\section{AUTHORS}

First Author - Abhishek Dutta, Post Graduate Diploma in Artificial Intelligence (PGDMLAI, IIIT-B), Regional Leader Mktg Analytics \& Data Science, Hewlett Packard Enterprise, abhishek.dta@gmail.com.

Second Author - Nivedita Roy, Master in Science, Applied Economics, Analytics Manager, Accenture, hiya_nivedita@yahoo.co.in.

\section{Correspondence Author - Abhishek Dutta,} abhishek.dta@gmail.com, +919900017453. 